\title{
INSIGHT responsive parenting intervention and infant feeding practices: randomized clinical trial
}

\author{
Jennifer S. Savage ${ }^{1,2^{*}} \mathbb{D}$, Emily E. Hohman ${ }^{1}$, Michele E. Marini ${ }^{1}$, Amy Shelly ${ }^{3}$, lan M. Paul ${ }^{3}$ and Leann L. Birch ${ }^{4}$
}

\begin{abstract}
Background: What, when, how, how much, and how often infants are fed have been associated with childhood obesity risk. The objective of this secondary analysis was to examine the effect of a responsive parenting (RP) intervention designed for obesity prevention on parents' infant feeding practices in the first year after birth.

Methods: Primiparous mother-newborn dyads were randomized to the Intervention Nurses Start Infants Growing on Healthy Trajectories (INSIGHT) Study RP intervention or child safety control. Research nurses delivered intervention content at home at infant age 3-4, 16, 28, and 40 weeks, and at a research center at 1 year. RP feeding guidance advised feeding that was contingent (i.e., feed in response to hunger and satiety signs, alternatives to using food to soothe), and developmentally appropriate (i.e., delaying introduction of solids, age-appropriate portion sizes). Infant feeding practices (i.e., bottle use, introduction of solids, food to soothe) were assessed by phone interviews and online surveys and dietary intake was assessed using a food frequency questionnaire.
\end{abstract}

Results: RP mothers were more likely to use of structure-based feeding practices including limit-setting $(p<0.05)$ and consistent feeding routines $(p<0.01)$ at age 1 year. RP group mothers were less likely to use non-responsive feeding practices such as pressuring their infant to finish the bottle/food $(p<0.001)$, and using food to soothe $(p<0.01)$, propping the bottle $(p<0.05)$ assessed between 4 and 8 months, and putting baby to bed with a bottle at age 1 year $(p<0.05)$. Few differences were seen between groups in what specific foods or food groups infants were fed.

Conclusions: Anticipatory guidance on RP in feeding can prevent the use of food to soothe and promote use of more sensitive, structure-based feeding which could reduce obesity risk by affecting how and when infants are fed during the first year.

Trial registration: The Intervention Nurses Start Infants Growing on Healthy Trajectories (INSIGHT) Study. www. clinicaltrials.gov. NCT01167270. Registered 21 July 2010.

Keywords: Obesity prevention, Infancy, Responsive parenting, Feeding practices and styles, Bottle-feeding and diet

\section{Background}

Epidemiological and laboratory findings point to early modifiable risk factors to prevent rapid weight gain and overweight $[1,2]$ including what, when, and how much an infant is fed [3]. What infants are fed in the first 24 months shapes their growth and subsequent dietary patterns [4], but how infants are fed can also influence

\footnotetext{
*Correspondence: jfs195@psu.edu

${ }^{1}$ Center for Childhood Obesity Research, 129 Noll Laboratory, The

Pennsylvania State University, University Park, PA 16802, USA

${ }^{2}$ Department of Nutritional Sciences, The Pennsylvania State University,

University Park, PA, USA

Full list of author information is available at the end of the article
}

early growth and development. There is evidence that US infants are often overfed, exceeding their estimated energy requirements [4].

Using a larger volume bottle to feed (i.e., $>6 \mathrm{oz}$ ) is associated with greater formula intake and rapid weight gain [5-7]. Controlling feeding practices, including pressuring the infant to finish the bottle and using feeding as the default response to any infant distress, reduced opportunities for infants self-regulation and can promote excessive weight gain [8]. In sum, how parents shape children's early experiences with food and eating, by teaching the child food rules and expectations, impacts 
child taste preferences, food choice, appetite regulation, dietary intake and obesity risk [9-13].

The theoretical framework for the Intervention Nurses Start Infants Growing on Healthy Trajectories (INSIGHT) trial is based on responsive parenting (RP). $\mathrm{RP}$ is defined as responding to the infant promptly, contingently, in ways that are developmentally appropriate [14]. Previous findings indicate that RP is associated with a range of positive child outcomes [15-18]. INSIGHT's central hypothesis was that responsive infant feeding guidance, focused on how to recognize and respond to infant hunger and fullness signs, could promote infant self-regulation, while also reducing the use of less responsive feeding practices (e.g., using feeding as the default response to any infant distress or promoting bottle emptying) would reduce risk for overeating and overweight among first-born infants [19]. This is based in part on evidence that feeding in response to infant hunger and fullness cues supports the development of appetite regulation (i.e., eating in response to hunger cues and not eating beyond satiation) [20, 21]. In contrast, use of non-responsive, coercive and controlling feeding practices, characterized by parents providing few opportunities for children to make choices about food and eating and to develop self-regulatory skills (e.g., feeding to quiet a distressed infant who is not hungry), can promote overfeeding, rapid weight gain and obesity risk [22-25].

The INSIGHT curriculum included guidance on feeding, including how to recognize and distinguish hunger from other distress, taught parents to accurately identify fullness signs to prevent overfeeding, instructed parents on a variety of alternative soothing strategies to manage infant crying (e.g., swaddling, non-nutritive sucking) to prevent the use of food as a first response to crying, and provided parents active learning opportunities to practice these skills with a trained nurse. Infants randomized to the INSIGHT RP intervention had slower weight gain during the first 6 months after birth and a reduced prevalence of overweight at 1 year [26]. The aim of this secondary analysis was to assess the proximal effects of the RP INSIGHT intervention on parent feeding styles and behaviors during the first year after birth. The hypothesis for this analysis was that responsive feeding practices would be more prevalent among mothers randomized to the RP group relative to control.

\section{Methods}

\section{Subjects and study design}

Mothers and newborns were recruited into the INSIGHT study from one maternity ward in central Pennsylvania between January 2012 and March 2014. Mothers were eligible for the study if they were primiparous, English-speaking, and $\geq 20$ years of age, and if their newborns were full-term ( $\geq 37$ weeks gestation), singleton, and weighed $\geq 2500 \mathrm{~g}$ at birth. Using a computer-generated algorithm, mother-infant dyads were randomized 2 weeks after delivery to either an RP intervention or a safety control group, stratified on birth weight for gestational age $(<50$ th percentile or $\geq 50$ th percentile) and intended milk-feeding type. A baseline survey was administered to mothers electronically. Further details on study design, recruitment/eligibility, and a CONSORT diagram have been previously published $[19,26]$.

Following randomization, preliminary intervention materials were mailed to all participants. As described previously [19], research nurses were trained in administering both the RP and safety control interventions at home visits conducted at child age 3-4, 16, 28, and 40 weeks, and research center visit at 52 weeks. 291 mother-infant dyads were randomized. 279 mother-infant dyads completed the first home visit at 34 weeks and are considered the study cohort for all outcomes and analyses as specified prior to study initiation. At 28 and 52 weeks, 269 (96.4\%) and 253 (90.7\%) dyads remained in the study, and there was no significant difference in attrition by study group. This study was approved by the Human Subjects Protection Office of the Penn State College of Medicine's Human Protection Office and registered at http://www.clinicaltrials.gov prior to participant enrollment. Mothers provided written consent for their and their infant's participation.

\section{RP intervention feeding-related components}

The INSIGHT intervention focused on RP in four domains of infant behavior: drowsy, sleeping, fussy, and alert and calm. A more detailed description of the RP and control curricula has been previously published [19]. Feeding guidance during infancy included (1) recognizing and responding appropriately to infant hunger and satiety cues; (2) age-appropriate, bottle-feeding practices (i.e., bottle size, nipple flow, transition off bottle); (3) delaying introduction to solids until 4-6 months; (4) promoting acceptance, liking, and intake of developmentally appropriate foods such as vegetables through repeated exposure; (5) serving age appropriate portions of healthy foods; and (6) using structure-based, non-controlling feeding practices that allow the infant to affect intake through shared control of the initiation and termination of feedings. Major themes of the feeding curriculum at each time point are listed in Table 1. RP guidance for fussy infants in the first year involved teaching parents to recognize hunger and distinguish hunger from other infant distress, and to how to use alternatives to feeding (e.g. swaddling, swinging, offering pacifier) to soothe/calm a fussy infant to promote healthy self-regulation development, including learning 
to self-soothe. The control group received an intervention that was similar in intensity, but focused on home safety. Feeding-related messaging in the safety curriculum was focused on food safety and choking prevention.

\section{Measures}

Phone interviews (conducted by study personnel other than the intervention nurses) and surveys were used to collect data. Online surveys, or paper surveys for those lacking Internet connectivity $(n=20)$, were sent to participants $2-3$ weeks prior to each visit. Data were collected and managed using REDCap [27]. A detailed list of measures has been published [19]. Demographic information was collected from participants at enrollment (e.g., parent and child race/ethnicity, marital status).

Table 1 Feeding messages in the responsive parenting intervention curriculum

\begin{tabular}{|c|c|c|c|c|}
\hline \multirow[t]{2}{*}{ Intervention component } & \multicolumn{4}{|c|}{ Child age in weeks } \\
\hline & $3-4$ & 16 & 28 & 40 \\
\hline \multicolumn{5}{|l|}{ What to feed } \\
\hline Only breastmilk or formula for first 4-6 months & $x$ & & & \\
\hline No cereal in bottle & $x$ & $x$ & & \\
\hline Avoid/limit fruit juice & $x$ & $x$ & $x$ & $x$ \\
\hline Portion sizes for complementary foods & & $x$ & $x$ & $x$ \\
\hline Fruits and vegetables & & $x$ & $x$ & $x$ \\
\hline Foods to limit & & $x$ & $x$ & $x$ \\
\hline Water & & & $x$ & $x$ \\
\hline Snacking & & & & $x$ \\
\hline Cow's milk & & & & $x$ \\
\hline \multicolumn{5}{|l|}{ When to feed } \\
\hline Introducing solids at 4-6 months & $x$ & $x$ & & \\
\hline Introducing cup at 6-9 months & & & $x$ & $x$ \\
\hline Weaned from bottle by 1 year & & & $x$ & $x$ \\
\hline Introducing a spoon & & & & $x$ \\
\hline \multicolumn{5}{|l|}{ How to feed } \\
\hline Bottle size \& nipple type & $x$ & $x$ & & \\
\hline Hunger and fullness cues & $x$ & $x$ & $x$ & \\
\hline Do not put to bed with bottle/cup & $x$ & $x$ & $x$ & $x$ \\
\hline Alternatives to using food to soothe & $x$ & $x$ & $x$ & $x$ \\
\hline Do not pressure child to eat & $x$ & $x$ & $x$ & $x$ \\
\hline Repeated exposure to new foods & & $x$ & $x$ & $x$ \\
\hline Modeling positive eating behavior & & $x$ & $x$ & $x$ \\
\hline Shared responsibility of feeding & & $x$ & $x$ & $x$ \\
\hline Mealtime routines & & & $x$ & $x$ \\
\hline Family meals & & & & $x$ \\
\hline Eating away from home & & & & $x$ \\
\hline Do not use food to reward/control behavior & & & & $x$ \\
\hline Purchasing and access to unhealthy foods & & & & $x$ \\
\hline
\end{tabular}

Maternal age, pre-pregnancy weight, gestational weight gain, and infant gestational age, sex, and birth weight and length were abstracted from medical charts.

\section{Bottle-feeding and breastfeeding practices}

Information on developmentally-relevant infant feeding practices was obtained at infant age $8,20,32$, and 52 weeks. Mothers were asked about bottle-feeding practices (i.e. bottle and nipple size, adding cereal to the bottle, putting child to bed with a bottle or sippy cup), formula and breastfeeding practices (what they were currently feeding, cessation of breastfeeding). Responsiveness to fullness signals was assessed by asking mothers how frequently they tried to get the infant to finish the bottle.

\section{Introduction of complementary foods}

Mothers reported on the introduction of solids (when and what foods were introduced first).

\section{Feeding beliefs and behaviors}

At 28 weeks, mothers completed the Infant Feeding Styles Questionnaire (IFSQ) designed to assess feeding beliefs and behaviors among parents of infants in 5 feeding style domains: laissez-faire, pressuring, restrictive, responsive, and indulgent [28]. In this analysis, results for the pressuring (pressure to finish, $\alpha=0.81$; pressure with cereal, $\alpha=0.83$; pressure to soothe, $\alpha=0.79$ ) restrictive (restrictive amount, $\alpha=0.74$; restrictive diet quality, $\alpha=$ $0.69)$, and responsive satiety $(\alpha=0.77)$ feeding styles are presented. The laissez-faire attention, laissez-faire diet quality, and responsive attention scales demonstrated poorer reliability ( $\alpha=0.62,0.53$, and 0.62 ) in our sample, while the indulgent subscale questions were not relevant at the 28 week time point, and thus these scales were not further analyzed.

At 1 year, the Structure and Control in Parent Feeding (SCPF) questionnaire was used to assess controlling feeding practices: Pressure to Eat $(\alpha=0.78)$ and Restriction $(\alpha=0.68)$ [29]. In addition, this scale assesses responsive feeding practices that may promote self-regulation, including Limiting Exposure to Unhealthy Foods $(\alpha=0.72)$ and Consistent Feeding Routines $(\alpha=0.76)$.

\section{Feeding to soothe}

Use of feeding to soothe a fussy infant was assessed at 8, 16, 32, and 44 weeks using items from the Baby's Basic Needs questionnaire [24]. This scale was modified to include contexts and situations when a mother could use feeding to soothe. An unweighted least squares exploratory factor analysis (EFA) was completed for the 21-item survey, using an equamax rotation (see Additional file 1). Items were iteratively removed based on loadings that 
were $<0.4$ producing a factor structure with 2 eigenvalues $>1$. Restricting the EFA to 2 factors gave factor loadings with simple structure, with two feeding-to-soothe factors: contextual ( 6 items, $\alpha=0.79$ ) and emotional ( 6 items; $\alpha=$ 0.90). Higher contextual feeding-to-soothe scores indicate greater use of feeding to soothe or quiet a distressed child in a variety of contexts (i.e., in a doctor's waiting room, in the car, before bed), without regard for whether hunger was the source of infant distress. Higher emotional feeding-to-soothe scores indicate greater use of feeding to soothe in response to either the infant's distress, or maternal stress, frustration, or anger. Mothers also rated the effectiveness of using feeding to soothe their infant on a scale of 1 (does not work) to 4 (works all of the time).

\section{Food intake}

Mothers reported the frequency of serving 24 beverages and 104 solid food items during the past week at 3-4, 16,28 , and 40 weeks to assess frequency of breast and formula feeding and complementary food intake on a food frequency questionnaire. Predominant breastfeeding was defined if $\geq 80 \%$ of milk feedings were breastmilk, [30] either at the breast or by bottle [25, 31]. Frequencies for other food and beverage items were recoded to times per day, and total times consumed per day for food groups (fruit -18 items, vegetables -22 items, sweets -12 items, salty snacks -5 items, sugar-sweetened beverages -7 items, and fried foods 3 items) were calculated. The percent of participants consuming each food group at least once in the past week and at least once per day was also calculated.

\section{Statistical analysis}

Data were analyzed using SAS 9.4 (SAS Institute, Cary, NC). The effect of study group on categorical outcomes was assessed using logistic regression, and effect on continuous variables was using ANOVA. Odds ratios and Cohen's D were calculated as indicators of effect size for logistic regression and ANOVA analyses, respectively. All analyses controlled for the randomization stratification variables. Effects of predominant milk-feeding type (breast vs. formula) and interactions between study group and milk-feeding type were also assessed for dietary outcomes. Significance was defined as $p<0.05$.

\section{Results}

Participating mothers were primiparous, predominantly white, non-Hispanic, married, and college educated with about 50\% reporting annual household incomes above $\$ 75,000$ (Table 2). There were no significant differences in baseline characteristics between the RP and control groups. At the 3-4 week home visit, $60.9 \%$ of infants were predominantly breastfed, and this dropped to $47.0 \%$ at 16 weeks, $37.0 \%$ at 28 weeks, and $32.7 \%$ at
40 weeks. There were no significant study group differences in the proportion of infants who were predominantly breastfed at any time point.

\section{Bottle-feeding practices}

As shown in Table 3, few participating mothers reported they were adding cereal to their child's bottle at 8 weeks, but at 20 weeks, fewer mothers in the RP group were adding cereal to the bottle $(8.4 \%$ vs $20.0 \%$ in the control group). At 1 year, children in the RP group were more likely to have transitioned their infant off the bottle (37.6\%) than children in the control group (21.1\%). The majority of mothers in both groups reported using a slow-flow nipple at 8 weeks, but at 20 weeks, a greater percentage of mothers in the RP group were still using a slow-flow nipple compared to those in the control group $(83 / 117(70.9 \%)$ vs $61 / 105(58.1 \%), p=0.050)$ (see Table 3$)$. There were no differences between groups in the percentage of mothers using a larger bottle size $(>8 \mathrm{oz})$ at 8,20 or 32 weeks. Fewer RP mothers reported propping the bottle at 28 weeks (10.1\%) compared to control (19.7\%). At age 1 year, more RP mothers were using a sippy cup than control. At 8, 20, and 32 weeks, the percentage of mothers who reported "ever" putting their child to bed with a bottle was relatively low and did not differ between groups, but at 52 weeks, fewer mothers in the RP group reported this behavior (10.4\% vs $20.3 \%$ in the control group). Mothers in the RP group also fed their infant fewer times at night (7 pm-7 am) than control at 20 and 32 weeks, but not 8 weeks.

\section{Transition to complementary foods}

In both the RP and control groups, the most common first food was infant cereal (71/124 (57.3\%) in the RP group and 72/124 (58.1\%) in control introduced cereal first), but among those who offered a different first food, mothers in the RP group were more likely to introduce vegetables first $(50 / 124(40.3 \%))$ compared to control (31/124 (25.0\%)). Mothers in the RP group reported introducing solids to their infant later than those in the control group (mean 22.0 \pm SD 3.9 weeks vs. $21.0 \pm$ 4.2 weeks, difference 1.0 (95\% CI: 0.04-1.98) weeks, $p=$ $0.04)$; however, the majority of mothers in both groups introduced solids between 4 and 6 months (17-26 weeks) $(\mathrm{RP}=113 / 140(80.7 \%)$, control $=117 / 139(84.2 \%))$, consistent with current guidance. Introduction before or after 6 months did not differ significantly between groups. Infants who were predominantly breastfed at 16 weeks were introduced to solids later than formula fed infants $(22.6 \pm 3.6$ weeks vs. $20.4 \pm 4.2$ weeks, $p=0.003$ ), but there was no interaction between study group and predominant milk-feeding type. 
Table 2 Participant demographics $(n=279)$

\begin{tabular}{|c|c|c|}
\hline & $\begin{array}{l}\mathrm{RP} \\
(n=140)\end{array}$ & $\begin{array}{l}\text { Control } \\
(n=139)\end{array}$ \\
\hline \multicolumn{3}{|l|}{ Infant } \\
\hline Male sex, N (\%) & $75(53.6)$ & 69 (49.6) \\
\hline Gestational age (weeks), mean (SD) & $39.6(1.2)$ & $39.5(1.1)$ \\
\hline Birth weight (kg), mean (SD) & $3.40(0.43)$ & $3.46(0.43)$ \\
\hline Birth length $(\mathrm{cm})$, mean (SD) & $50.9(2.4)$ & $51.0(2.1)$ \\
\hline \multicolumn{3}{|l|}{ Mother } \\
\hline Age (years), mean (SD) & $28.7(4.6)$ & $28.7(4.9)$ \\
\hline Pre-pregnancy BMI, mean (SD) & $25.5(5.0)$ & $25.3(5.6)$ \\
\hline Gestational weight gain (kg), mean (SD) & $15.6(6.4)$ & $15.0(6.0)$ \\
\hline Diabetes during pregnancy, $N(\%)$ & $6(4.3)$ & $13(9.4)$ \\
\hline Smoked during pregnancy, N (\%) & $12(8.6)$ & $9(6.5)$ \\
\hline \multicolumn{3}{|l|}{ Race, $N(\%)$} \\
\hline Black & $10(7.1)$ & $7(5.0)$ \\
\hline White & $122(87.1)$ & $127(91.4)$ \\
\hline Native Hawaiian or Pacific Islander & $1(0.7)$ & $0(0)$ \\
\hline Asian & $5(3.6)$ & $4(2.9)$ \\
\hline Other & $2(1.4)$ & $1(0.7)$ \\
\hline \multicolumn{3}{|l|}{ Ethnicity, N (\%) } \\
\hline Hispanic/Latino & $12(8.6)$ & $7(5.0)$ \\
\hline \multicolumn{3}{|l|}{ Marital status, N (\%) } \\
\hline Married & $102(72.9)$ & $108(77.7)$ \\
\hline Not married, living with partner & $25(17.9)$ & $19(13.7)$ \\
\hline Single & $12(8.6)$ & $12(8.6)$ \\
\hline Divorced/separated & $1(0.7)$ & $0(0)$ \\
\hline \multicolumn{3}{|l|}{ Annual household income, N (\%) } \\
\hline$<\$ 10,000$ & $6(4.3)$ & $5(3.6)$ \\
\hline$\$ 10,000-\$ 24,999$ & $10(7.1)$ & $10(7.2)$ \\
\hline$\$ 25,000-\$ 49,999$ & $5(3.6)$ & $23(16.6)$ \\
\hline$\$ 50,000-\$ 74,999$ & $46(32.9)$ & $26(18.7)$ \\
\hline$\$ 75,000-\$ 99,999$ & $32(22.9)$ & $23(16.6)$ \\
\hline$\$ 100,000$ or more & $32(22.9)$ & $43(30.9)$ \\
\hline Do not know or refuse to answer & $9(6.4)$ & $9(6.4)$ \\
\hline \multicolumn{3}{|l|}{ Education, $N(\%)$} \\
\hline HS graduate or less & $16(11.4)$ & $16(11.5)$ \\
\hline Some college & $37(26.4)$ & $36(25.9)$ \\
\hline College graduate & $48(34.3)$ & $52(37.4)$ \\
\hline Graduate degree + & 39 (27.9) & $35(25.2)$ \\
\hline
\end{tabular}

\section{Use of pressure, restriction, and structure in infant feeding}

As shown in Table 4, at 8, 20, and 32 weeks, mothers in the parenting group were less likely to report that they encouraged their child to finish the bottle if their infant stopped drinking before the milk was gone. In addition, more mothers in the control group reported "ever" trying to get their child to finish breastmilk/formula or food at 28 weeks, but not at 16 weeks, compared to RP mothers. At 28 weeks, mothers in the RP group had lower scores on all three pressure subscales of the IFSQ (pressure to finish, pressure to soothe, and pressure with cereal) than mothers in the control group (Table 4); there was no difference on restriction or responsive satiety. At 52 weeks, mothers in the RP group reported lower use of pressure to eat and greater use of the two structure-based feeding scales, limiting exposure to unhealthy foods, and consistent feeding routines.

\section{Use of feeding to soothe (feeding as the "default" to soothe a fussy infant)}

Fewer mothers in the RP group reported using feeding as the first response, immediately feeding their child when they cried at 16 weeks and 28 weeks in the absence of hunger cues (Table 5). At 8, 16, 32 and 44 weeks, mothers in the RP group reported less frequent context-based and emotion-based use of food to soothe (Table 5). At 16 weeks, RP mothers were less likely to use context-based feeding to soothe "sometimes or more often" (39/130 (30.0\%) RP vs 56/123 (45.5\%) control, $p=0.01$ ). Fewer RP mothers reported ever using emotion-based feeding-to-soothe at 16 weeks (42/125 $(33.6 \%)$ vs $59 / 116(53.6 \%), p=0.008)$ context-based feeding-to-soothe at 44 weeks $(69 / 116(59.5 \%)$ vs $94 / 118$ (79.7\%), $p=0.007$ ) and emotion-based feeding-to-soothe at 44 weeks $(19 / 115(16.5 \%)$ vs $36 / 117(30.8 \%), p=0.01)$ than control. At 16 weeks, mothers in the RP group reported that beverages (breastmilk/formula and other beverages) were less effective at soothing their infant than mothers in the control group. At 32 weeks, RP mothers reported lower effectiveness of both beverages and foods to soothe their child than control. At 44 weeks, RP mothers reported lower effectiveness of beverages, but not foods than control.

\section{Food intake}

At 1 year, there were few differences between groups in dietary intake as measured by the FFQ. Fewer mothers in the RP group reported that their child consumed salty snacks (chips, crackers, pretzels, etc.) on a daily basis compared to the control group (12/122 (9.8\%) vs $24 / 118$ $(20.3 \%), p=0.03)$, and more mothers in the RP group reported that their child consumed vegetables daily (117/ $122(95.9 \%)$ vs $105 / 118$ (89.0\%), $p=0.049)$, but there were no study group differences in reported daily or weekly exposure to fruit juice, sugar sweetened-beverages, sweets, fried foods, or fruit. Mothers who were predominantly breastfeeding at 16 weeks were less likely to report that their child consumed any sugar sweetened beverages $(6 / 120(5.0 \%)$ vs $21 / 119(17.7 \%), p=0.02)$ or fruit juice (46/122 (37.7\%) vs. $74 / 124(59.7 \%), p=0.009)$ in the past 
Table 3 Effect of RP intervention on bottle feeding

\begin{tabular}{|c|c|c|c|c|}
\hline & $\begin{array}{l}\mathrm{RP} \\
(n=140)\end{array}$ & $\begin{array}{l}\text { Control } \\
(n=139) \\
\end{array}$ & $p$-value ${ }^{a}$ & Odds ratio $(\mathrm{Cl})$ or Cohen's $\mathrm{D}$ \\
\hline \multicolumn{5}{|c|}{ Currently adding cereal to bottle (denominator = current bottle users) } \\
\hline 8 weeks & $6 / 114(5.3 \%)$ & $2 / 112(1.8 \%)$ & 0.18 & $3.1(0.6-15.6)$ \\
\hline 20 weeks & $10 / 119(8.4 \%)$ & $22 / 110(20.0 \%)$ & 0.01 & $0.4(0.2-0.8)$ \\
\hline 32 weeks & $11 / 108(10.2 \%)$ & 15/107 (14.0\%) & 0.38 & $0.7(0.3-1.6)$ \\
\hline \multicolumn{5}{|c|}{ Uses slow flow nipple (denominator = current bottle users) } \\
\hline 8 weeks & $101 / 114(88.6 \%)$ & $86 / 107(80.4 \%)$ & 0.10 & $1.9(0.9-4.0)$ \\
\hline 20 weeks & $83 / 117(70.9 \%)$ & $61 / 105(58.1 \%)$ & 0.05 & $1.8(1.0-3.2)$ \\
\hline \multicolumn{5}{|c|}{ Use bottle $\geq 8$ oz. (denominator = current bottle users) } \\
\hline 8 weeks & 10/111 (9.0\%) & $15 / 106(14.1 \%)$ & 0.26 & $0.6(0.3-1.4)$ \\
\hline 20 weeks & $37 / 117(31.6 \%)$ & 43/105 (40.9\%) & 0.17 & $0.7(0.4-1.2)$ \\
\hline 32 weeks & 49/103 (47.6\%) & $57 / 102(55.9 \%)$ & 0.28 & $0.7(0.4-1.3)$ \\
\hline \multicolumn{5}{|c|}{ Prop/Propped the bottle (denominator = all available) } \\
\hline 16 weeks & 17/122 (13.9\%) & $22 / 117(18.6 \%)$ & 0.30 & $0.7(0.3-1.4)$ \\
\hline 28 weeks & $13 / 129(10.1 \%)$ & $24 / 122(19.7 \%)$ & 0.03 & $0.4(0.2-0.9)$ \\
\hline \multicolumn{5}{|c|}{ Using bottle (denominator = all available) } \\
\hline 52 weeks & $78 / 125(62.4 \%)$ & $97 / 123(78.9 \%)$ & 0.005 & $0.4(0.3-0.8)$ \\
\hline \multicolumn{5}{|c|}{ Using sippy cup (denominator = all available) } \\
\hline 32 weeks & $54 / 128(42.2 \%)$ & $42 / 129(32.6 \%)$ & 0.11 & $1.5(0.9-2.5)$ \\
\hline 52 weeks & $124 / 125(99.2 \%)$ & $113 / 125(90.4 \%)$ & 0.01 & $13.2(1.7-104)$ \\
\hline \multicolumn{5}{|c|}{ Using regular cup (denominator = all available) } \\
\hline 32 weeks & 9/127 (7.1\%) & 10/131 (7.6\%) & 0.85 & $0.9(0.4-2.3)$ \\
\hline 52 weeks & $14 / 125(11.2 \%)$ & $9 / 125(7.2 \%)$ & 0.29 & $1.6(0.7-3.9)$ \\
\hline \multicolumn{5}{|c|}{ Puts child to bed with bottle/sippy cup (denominator = current bottle or sippy cup users) } \\
\hline 8 weeks & $0 / 114(0 \%)$ & $3 / 108(2.8 \%)$ & 0.95 & NA \\
\hline 20 weeks & 2/118 (1.7\%) & $3 / 106(2.8 \%)$ & 0.56 & $0.6(0.1-3.6)$ \\
\hline 32 weeks & $6 / 114(5.3 \%)$ & $9 / 113(7.8 \%)$ & 0.42 & $0.6(0.2-1.9)$ \\
\hline 52 weeks & $13 / 125(10.4 \%)$ & 25/122 (20.5\%) & 0.03 & $0.5(0.2-0.9)$ \\
\hline \multicolumn{5}{|c|}{ Night-time (7 pm-7 am) feedings - mean (SD) } \\
\hline 8 weeks & $3.1(1.2), n=127$ & $3.3(1.3), n=130$ & 0.20 & 0.16 \\
\hline 20 weeks & $1.8(1.2), n=123$ & $2.2(1.3), n=123$ & 0.03 & 0.32 \\
\hline 32 weeks & $1.3(1.1), n=122$ & $1.7(1.4), n=121$ & 0.01 & 0.32 \\
\hline
\end{tabular}

${ }^{a} p$ for study group difference, ANOVA or logistic regression adjusted for stratification variables

week at 1 year than those that formula feeding at 16 weeks, but there was no interaction between predominant milk-feeding type and study group (data not shown). There were no other significant differences in daily or weekly exposure to food groups by predominant milk feeding type.

\section{Discussion}

Results provide support that the RP intervention influenced how first-time mothers were feeding their infants, and to a lesser extent what infants were fed. The RP mothers reported both less frequent use of non-responsive feeding practices that could promote excessive intake (i.e., feeding to soothe, pressuring to finish a bottle) and more frequent use of structure-based feeding (i.e., limit-setting, consistent feeding routines). Compared to control mothers, RP mothers also reported that feeding was less effective at soothing their infant. This may be because mothers were using alternatives to using food to soothe (e.g., swaddling swinging, pacifier), instead of using food as a first response to crying. Combined with evidence of the RP intervention's effects on infant sleep health and dietary intake patterns [32, 33], data from this study contribute to identification of modifiable parenting behaviors associated with less rapid infant weight gain from birth to 28 weeks and lowered risk 
Table 4 Effect of RP intervention on maternal pressure, restriction, and structure in feeding

\begin{tabular}{|c|c|c|c|c|}
\hline & $\begin{array}{l}\mathrm{RP} \\
(n=140)\end{array}$ & $\begin{array}{l}\text { Control } \\
(n=139)\end{array}$ & $p$-value ${ }^{a}$ & Odds ratio $(\mathrm{Cl})$ or Cohen's $\mathrm{D}$ \\
\hline \multicolumn{5}{|l|}{ Pressuring feeding } \\
\hline \multicolumn{5}{|c|}{ Child is encouraged to finish a bottle if baby stops drinking before the milk is all gone ( $\geq$ sometimes, denominator $=$ current bottle users) } \\
\hline 8 weeks & $38 / 114(33.3 \%)$ & $56 / 108(51.4 \%)$ & 0.007 & $0.5(0.3-0.8)$ \\
\hline 20 weeks & $41 / 117(35.0 \%)$ & $53 / 105(50.5 \%)$ & 0.02 & $0.5(0.3-0.9)$ \\
\hline 32 weeks & $36 / 109(33.0 \%)$ & $65 / 106(61.3 \%)$ & $<0.0001$ & $0.3(0.2-0.5)$ \\
\hline \multicolumn{5}{|c|}{ Try to get my child to finish breastmilk or formula (denominator = all available) } \\
\hline \multicolumn{5}{|l|}{16 weeks } \\
\hline Never & $48 / 132(36.4 \%)$ & $39 / 131(29.8 \%)$ & 0.06 & $0.7(0.4-1.0)$ \\
\hline Rarely & $43 / 132(32.6 \%)$ & $41 / 131(31.3 \%)$ & & \\
\hline Half of the time & $23 / 132(17.4 \%)$ & $21 / 131(16.0 \%)$ & & \\
\hline Most of the time & $16 / 132(12.1 \%)$ & $22 / 131(16.8 \%)$ & & \\
\hline Always & $2 / 132(1.5 \%)$ & $8 / 131(6.1 \%)$ & & \\
\hline \multicolumn{5}{|l|}{28 weeks } \\
\hline Never & $46 / 128(35.9 \%)$ & $22 / 125(17.6 \%)$ & $<0.0001$ & $0.4(0.2-0.6)$ \\
\hline Rarely & $54 / 128(42.2 \%)$ & $47 / 125(37.6 \%)$ & & \\
\hline Half of the time & $11 / 128(8.6 \%)$ & $26 / 125(20.8 \%)$ & & \\
\hline Most of the time & $14 / 128(10.9 \%)$ & $18 / 125(14.4 \%)$ & & \\
\hline Always & $3 / 128(2.3 \%)$ & $12 / 125(9.6 \%)$ & & \\
\hline \multicolumn{5}{|c|}{ Try to get my child to finish his/her food (denominator = all available) } \\
\hline \multicolumn{5}{|l|}{28 weeks } \\
\hline Never & $42 / 128(32.8 \%)$ & $16 / 119(13.5 \%)$ & 0.0001 & $0.4(0.3-0.6)$ \\
\hline Rarely & $43 / 128(33.6 \%)$ & $43 / 119(36.1 \%)$ & & \\
\hline Half of the time & $23 / 128(18.0 \%)$ & $24 / 119(20.2 \%)$ & & \\
\hline Most of the time & $17 / 128(13.3 \%)$ & $27 / 119(22.7 \%)$ & & \\
\hline Always & $3 / 128(2.3 \%)$ & $9 / 119(7.6 \%)$ & & \\
\hline \multicolumn{5}{|c|}{ Infant Feeding Styles Questionnaire (IFSQ) - 28 weeks } \\
\hline Pressure to finish & $1.85(0.61), n=130$ & $2.24(0.74), n=128$ & $<0.0001$ & 0.58 \\
\hline Pressure to soothe & $1.71(0.62), n=130$ & $2.23(0.82), n=128$ & $<0.0001$ & 0.72 \\
\hline Pressure with cereal & $1.39(0.65), n=130$ & $1.73(0.90), n=128$ & 0.0003 & 0.43 \\
\hline Restrictive/amount & $2.84(1.05), n=130$ & $2.93(1.03), n=128$ & 0.48 & 0.09 \\
\hline Restrictive/diet quality & $3.93(0.69), n=130$ & $3.87(0.77), n=128$ & 0.51 & 0.08 \\
\hline Responsive/satiety & $4.62(0.41), n=130$ & $4.56(0.48), n=127$ & 0.29 & 0.13 \\
\hline \multicolumn{5}{|c|}{ Structure and Control in Parenting Feeding (SCPF) - 52 weeks } \\
\hline Limit exposure & $4.13(0.40), n=120$ & $4.01(0.47), n=123$ & 0.03 & 0.27 \\
\hline Consistent feeding routines & $4.18(0.48), n=120$ & $4.00(0.49), n=123$ & 0.006 & 0.37 \\
\hline Pressure to eat & $1.78(0.62), n=120$ & $1.99(0.68), n=123$ & 0.01 & 0.32 \\
\hline Restriction & $2.12(0.88), n=120$ & $2.03(0.85), n=123$ & 0.42 & 0.10 \\
\hline
\end{tabular}

${ }^{a} p$ for study group difference, ANOVA or logistic regression adjusted for stratification variables

of overweight at $1 \mathrm{y}$ as previously described [26]. INSIGHT was designed as a multicomponent RP intervention based on the perspective that infant feeding is a key aspect of early caregiving related to infant arousal (i.e., fussing and crying), sleep, and active social play. Although our RP approach is novel with respect to early obesity prevention, these findings provide one more piece of evidence that RP guidance can promote beneficial parenting and child outcomes [15-18].

INSIGHT RP guidance focused on feeding in response to infant hunger and fullness, and on alternative soothing strategies to calm a non-hungry, distressed infant. 
Table 5 Effect of RP intervention on use of feeding to soothe, mean (SD)

\begin{tabular}{|c|c|c|c|c|}
\hline & $\begin{array}{l}\text { Parenting } \\
(n=140)\end{array}$ & $\begin{array}{l}\text { Control } \\
(n=139)\end{array}$ & $p$-value ${ }^{c}$ & Odds ratio $(\mathrm{Cl})$ or Cohen's D \\
\hline \multicolumn{5}{|c|}{ When infant cries, I immediately feed (denominator = all available) } \\
\hline \multicolumn{5}{|l|}{16 weeks } \\
\hline Never & $33 / 131(25.2 \%)$ & $18 / 129(14.0 \%)$ & 0.01 & $0.6(0.4-0.9)$ \\
\hline Seldom & $57 / 131(43.5 \%)$ & $58 / 129(45.0 \%)$ & & \\
\hline Half of the time & $34 / 131(26.0 \%)$ & $37 / 129(28.7 \%)$ & & \\
\hline Most of the time & $7 / 131(5.3 \%)$ & $11 / 129(8.5 \%)$ & & \\
\hline Always & $0 / 131(0 \%)$ & $5 / 129(3.9 \%)$ & & \\
\hline \multicolumn{5}{|l|}{28 weeks } \\
\hline Never & $51 / 128(39.8 \%)$ & $33 / 126(26.2 \%)$ & 0.0009 & $0.5(0.3-0.7)$ \\
\hline Seldom & $52 / 128(40.6 \%)$ & $46 / 126(36.5 \%)$ & & \\
\hline Half of the time & $23 / 128(18.0 \%)$ & $36 / 126(28.6 \%)$ & & \\
\hline Most of the time & $2 / 128(1.6 \%)$ & $8 / 126(6.4 \%)$ & & \\
\hline Always & 0/128 (0\%) & $3 / 126(2.4 \%)$ & & \\
\hline \multicolumn{5}{|c|}{ Food to soothe: Context-based ${ }^{a}$} \\
\hline 8 weeks & $2.57(0.81), n=129$ & $2.83(0.72), n=119$ & 0.008 & 0.34 \\
\hline 16 weeks & $2.50(0.74), n=130$ & $2.76(0.84), n=123$ & 0.009 & 0.33 \\
\hline 32 weeks & $2.00(0.62), n=117$ & $2.43(0.82), n=112$ & $<0.0001$ & 0.59 \\
\hline 44 weeks & $2.16(0.70), n=116$ & $2.56(0.76), n=118$ & $<0.0001$ & 0.55 \\
\hline \multicolumn{5}{|c|}{ Food to soothe: Emotion-based ${ }^{a}$} \\
\hline 8 weeks & $1.78(0.94), n=128$ & $2.01(0.92), n=110$ & 0.07 & 0.25 \\
\hline 16 weeks & $1.57(0.77), n=125$ & $1.90(0.89), n=116$ & 0.002 & 0.40 \\
\hline 32 weeks & $1.36(0.50), n=117$ & $1.65(0.71), n=110$ & 0.0003 & 0.47 \\
\hline 44 weeks & $1.31(0.47), n=115$ & $1.62(0.71), n=117$ & 0.0001 & 0.51 \\
\hline \multicolumn{5}{|c|}{ Food to soothe efficacy: Beverages ${ }^{b}$} \\
\hline 8 weeks & $3.09(0.72), n=129$ & $3.31(0.69), n=122$ & 0.02 & 0.31 \\
\hline 16 weeks & $2.93(0.76), n=123$ & $3.15(0.68), n=128$ & 0.01 & 0.31 \\
\hline 32 weeks & $2.55(0.77), n=100$ & $2.77(0.75), n=104$ & 0.03 & 0.29 \\
\hline 44 weeks & $2.36(0.70), n=97$ & $2.56(0.75), n=104$ & 0.046 & 0.28 \\
\hline \multicolumn{5}{|c|}{ Food to soothe efficacy: Solid Foods ${ }^{2}$} \\
\hline 32 weeks & $1.83(0.48), n=46$ & $2.06(0.45), n=54$ & 0.02 & 0.49 \\
\hline 44 weeks & $2.03(0.46), n=58$ & $2.11(0.57), n=73$ & 0.43 & 0.15 \\
\hline
\end{tabular}

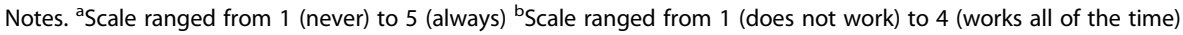

$c_{p}$ for study group difference, ANOVA or logistic regression adjusted for stratification variables

Early in infancy, when exclusively milk-fed, infants are learning which cues are associated with initiation and termination of eating [34]. Infants need to learn to discriminate hunger from other distress, requiring sensitive parenting. In other words, parents should feed in response to hunger, but use other non-food approaches with distress that is not hunger-related (e.g., tired, scared, overstimulated). Repeated use of feeding to soothe a distressed, non-hungry infant pairs feeding with removal of non-hunger distress cues has been shown to influence infant weight $[8,24,35]$. Although the mechanism is not clear, preschool children whose mothers report greater use of food to regulate their infant's emotions have infants who are more likely to develop emotional eating styles and poorer diets [36, 37].

In this study, relative to the control, RP mothers reported that feeding was a less effective way to soothe their infant, which could have persistent effects on how mothers use food to manage child behavior as the child develops [38]. Using food to soothe infant distress could result in conditioned eating in response to negative emotions, a characteristic of emotional eaters that is associated with obesity in older children [39, 40]. More evidence is needed, but is it possible that children are 
learning to eat in response to emotional cues. Pressuring the infant to finish the bottle can also increase infant intake and perhaps affect the extent to which infants attend to or ignore fullness cues in determining meal termination. Over time this can affect learning by shaping the extent to which internal fullness cues and amount of food remaining affect amount consumed, and ability to self-regulate. Serving children larger portions promotes increased intake [41] and other experimental research with young children has shown that pressuring children to eat in order to finish consuming food on their plate can promote greater intake [38, 42-45].

RP intervention parents were less likely to report that they used feeding as the immediate, default response to infant crying and reported less frequent use of feeding to soothe. Compared to control, mothers in the RP group reported that both milk and solid foods were less effective at soothing their infant. This may because RP mothers had learned to use alternative approaches to soothing the infant, or they paid closer attention to their infant's signals, using soothing techniques to calm a distressed infant, although direct evidence on this point is lacking. Infants cry for many reasons, hunger being just one. A potential explanation is that the RP group may just be less dependent on using food for non-nutritive soothing. Together, findings from this study provide support that an early parenting intervention can affect how and in what contexts infants are being fed, at least among first-time parents, and that how infants are fed can impact growth and weight outcomes.

Although The INSIGHT RP curriculum also targeted what foods infants consumed by providing traditional nutrition education to parents on age-appropriate foods and portions, results indicate that the RP intervention had very limited effects on what drinks and foods were consumed; the INSIGHT $\mathrm{RP}$ intervention did not affect the extent to which infants were offered fruit juice, sugar sweetened beverages, sweet foods, or fried foods at age 1 year. We previously reported differences in dietary patterns at 9 months between RP and control, particularly among formula-fed infants [33]. However, it is plausible that by age 1 year, most infants had nearly completed the transition to consuming diets very similar to those of other family members. Given this and the few observed group differences on diet quality, novel family-based interventions targeting the home food and eating environment may be needed to impact the family diet during this critical developmental period when the infant is transitioning to the adult diet. It is unlikely that interventions can impact "what" foods infants and toddlers are exposed to without also changing what their parents are eating.
A study limitation is that all feeding behavior and food intake data were self-reported; RP mothers may have provided socially desirable responses. However, differences between treatment groups were much less evident for what was fed (e.g., sugar sweetened beverages, sweet and salty foods, fruits and vegetables), despite the fact that it is common knowledge that some foods are considered to be healthy for children (e.g., vegetables) and others are not (e.g., SSBs, fried foods). Mothers may have systematically under-reported the "unhealthy" foods. In addition to INSIGHT guidance on feeding, parents receive messages about what to eat and what not to eat from many other sources, including their pediatricians, the Special Supplemental Nutrition program for Women, Infants, and Children (WIC), in addition to pervasive marketing. This provides additional evidence for including 0 2 years in the Dietary Guidelines. Given the INSIGHT findings and national data, novel interventions targeting the family eating environment may be needed to impact the family diet when the infant is transitioning to the adult diet. Lastly, our sample was relatively demographically homogenous and is not nationally representative, limiting the generalizability of our findings.

\section{Conclusions}

The INSIGHT RP intervention affected maternal feeding practices. During the first year, RP mothers were consistently less likely to report using feeding to soothe their infant for reasons other than hunger, and less likely to report that feeding was an effective strategy for soothing their infant. Because RP mothers learned that alternative soothing strategies could be effective in soothing their infant, they may have been less likely to feed in response to contextual or emotional cues. RP mothers were also encouraged to terminate feedings in response to infant cues. RP mothers were less likely to report trying to get their infant to finish a bottle or other food. In contrast, $\mathrm{RP}$ mothers were more likely to use structure and routines in feeding. Taken together, these early differences in maternal feeding suggest that RP and control infants may have had different early experiences with feeding; in particular, the extent to which environmental or internal cues predicted the onset and termination of feedings, affecting the extent to which infants eat in response to hunger or in response to other distress. Findings support the view that providing anticipatory guidance on RP in feeding can promote use of more sensitive, structurebased feeding, which could reduce obesity risk by affecting how and when infants are fed. These findings, in combination with others from INSIGHT indicate that the RP intervention can affect multiple outcomes including feeding, sleeping [32] and early growth and obesity risk in infancy [26]. 


\section{Additional file}

Additional file 1: Appendix 1. Factor loadings for questionnaire items indicating contextual and emotional food-to-soothe feeding practices. Exploratory factor analysis was completed using unweighted least squares with an equamax rotation, restricting to 2 factors. $(N=197)$. (PDF $500 \mathrm{~kb}$ )

\section{Abbreviations}

BMI: Body Mass Index; INSIGHT: Intervention Nurses Start Infants Growing on Healthy Trajectories; RP: Responsive Parenting

\section{Acknowledgements}

This project is supported by grant R01DK088244 from the National Institute of Diabetes and Digestive and Kidney Diseases (NIDDK). Additional support was received from the Children's Miracle Network at Penn State Hershey Children's Hospital. The authors acknowledge Jodi Mindell, PhD, Jessica Beiler, MPH, Jennifer Stokes, RN, Patricia Carper, RN, Gabrielle Murray, RN, Heather Stokes, Nicole Verdiglione, Susan Rzucidlo, MSN, RN, Lindsey Hess, MS, Chelsea Rose, PhD, Katherine Balantekin, PhD, RD, Julia Bleser, MS, and Eric Loken, PhD, for their assistance with this project.

\section{Ethics approval to participate}

This study was approved by the Human Subjects Protection Office of the Penn State College of Medicine's Human Protection Office and registered at http://www.clinicaltrials.gov prior to participant enrollment.

\section{Funding}

This research was supported by grant R01DK088244. Additional support was received from the Children's Miracle Network at Penn State Children's Hospital. USDA Grant \# 2011-67001-30117 supported graduate students. REDCap support was received from The Penn State Clinical \& Translational Research Institute, Pennsylvania State University CTSA, NIH/NCATS Grant Number UL1 TR000127.

\section{Availability of data and materials}

The datasets used and/or analysed during the current study are available from the corresponding author on reasonable request.

\section{Authors' contributions}

JSS - contributed to the design of the study, intervention curriculum development, assisted with data analysis, drafted the manuscript, participated in critical revision of the manuscript, and approved the final manuscript as submitted. EEH - contributed to the data management, performed data analyses, drafted the results section, participated in critical revision of the manuscript, and approved the final manuscript as submitted. MEM - led the data management, performed factor analyses, assisted in drafting the results section, participated in critical revision of the manuscript, and approved the final manuscript as submitted. AS - participated in intervention design and delivery, participated in critical revision of the manuscript, and approved the final manuscript as submitted. IMP - co-led all aspects of the study concept, design, and participated in critical revision of the manuscript, and approved the final manuscript as submitted. LLB - coled all aspects of the study concept, design, and analysis, participated in critical revision of the manuscript, and approved the final manuscript as submitted. All authors read and approved the final manuscript.

\section{Consent for publication}

Not Applicable.

\section{Competing interests}

The other authors have no financial disclosures relevant to this article. The authors have no conflicts of interest relevant to this article.

\section{Publisher's Note}

Springer Nature remains neutral with regard to jurisdictional claims in published maps and institutional affiliations.

\section{Author details}

${ }^{1}$ Center for Childhood Obesity Research, 129 Noll Laboratory, The Pennsylvania State University, University Park, PA 16802, USA. ²Department of Nutritional Sciences, The Pennsylvania State University, University Park, PA, USA. ${ }^{3}$ Pediatrics and Public Health Sciences, Penn State College of Medicine, Hershey, PA, USA. ${ }^{\text {Department }}$ of Foods and Nutrition, University of Georgia, Athens, GA, USA.

Received: 18 November 2017 Accepted: 28 June 2018

Published online: 09 July 2018

\section{References}

1. Paul IM, Bartok CJ, Downs DS, Stifter CA, Ventura AK, Birch LL. Opportunities for the primary prevention of obesity during infancy. Adv Pediatr. 2009:56: 107-33.

2. Woo Baidal JA, Locks LM, Cheng ER, Blake-Lamb TL, Perkins ME, Taveras EM. Risk factors for childhood obesity in the first 1,000 days: A Systematic Review. Am J Prev Med. 2016;50(6):761-79.

3. Birch LL, Fisher JO. Development of eating behaviors among children and adolescents. Pediatrics. 1998:101(3 Pt 2):539-49.

4. Reidy KC, Deming DM, Briefel RR, Fox MK, Saavedra JM, Eldridge AL. Early development of dietary patterns: transitions in the contribution of food groups to total energy-feeding infants and toddlers study, 2008. BMC Nutrition. 2017:3(5)

5. Wood CT, Skinner AC, Yin HS, Rothman RL, Sanders LM, Delamater A, et al. Association between bottle size and formula intake in 2-month-old infants. Acad Pediatr. 2016;16(3):254-9.

6. Wood CT, Skinner AC, Yin HS, Rothman RL, Sanders LM, Delamater AM, et al. Bottle size and weight gain in formula-fed infants. Pediatrics. 2016;138(1)

7. Saavedra JM, Deming D, Dattilo A, Reidy K. Lessons from the feeding infants and toddlers study in North America: what children eat, and implications for obesity prevention. Ann Nutr Metab. 2013;62(Suppl 3):27-36.

8. Stifter CA, Moding KJ. Understanding and measuring parent use of food to soothe infant and toddler distress: a longitudinal study from 6 to 18 months of age. Appetite. 2015;95:188-96.

9. Hardy R, Wadsworth M, Kuh D. The influence of childhood weight and socioeconomic status on change in adult body mass index in a British national birth cohort. Int J Obes. 2000;24:725-34.

10. Hendy HM. Effectiveness of trained peer models to encourage food acceptance in preschool children. Appetite. 2002;39(3):217-25.

11. Lee S, Reicks M. Environmental and behavioral factors are associated with the calcium intake of low-income adolescent girls. J Am Diet Assoc. 2003; 103(11):1526-9.

12. Young EM, Fors SW, Hayes DM. Associations between perceived parent behaviors and middle school student fruit and vegetable consumption. J Nutr Educ Behav. 2004;36(1):2-8.

13. Cullen KW, Baranowski T, Rittenberry L, Cosart C, Hebert D, de Moor C. Child-reported family and peer influences on fruit, juice and vegetable consumption: reliability and validity of measures. Health Educ Res. 2001; 16(2):187-200

14. Eshel N, Daelmans B, de Mello MC, Martines J. Responsive parenting: interventions and outcomes. Bull World Health Organ. 2006;84(12):991-8.

15. Bernier A, Carlson SM, Deschenes M, Matte-Gagne C. Social factors in the development of early executive functioning: a closer look at the caregiving environment. Dev Sci. 2012;15(1):12-24.

16. Guttentag CL, Landry SH, Williams JM, Baggett KM, Noria CW, Borkowski JG, et al. "My Baby \& me": effects of an early, comprehensive parenting intervention on at-risk mothers and their children. Dev Psychol. 2014;50(5): 1482-96.

17. Sulik MJ, Blair C, Mills-Koonce R, Berry D, Greenberg M, Family Life Project I. Early parenting and the development of externalizing behavior problems: longitudinal mediation through Children's executive function. Child Dev. 2015;86(5):1588-603

18. Dexter CA, Wong K, Stacks AM, Beeghly M, Barnett D. Parenting and attachment among low-income African American and Caucasian preschoolers. J Fam Psychol. 2013;27(4):629-38.

19. Paul IM, Williams JS, Anzman-Frasca S, Beiler JS, Makova KD, Marini ME, et al. The intervention nurses start infants growing on healthy trajectories (INSIGHT) study. BMC Pediatr. 2014;14:184.

20. Karreman A, van Tuijl C, van Aken MAG, Deković M. Parenting and selfregulation in preschoolers: a meta-analysis. Infant Child Dev. 2006;15(6):561-79. 
21. Houck GM. Maternal limit setting during toddlerhood, delay of gratification, and behavior problems at age five. Infant Mental Health J. 2004;25(1):28-46.

22. Rifas-Shiman SL, Sherry B, Scanlon K, Birch LL, Gillman MW, Taveras EM. Does maternal feeding restriction lead to childhood obesity in a prospective cohort study? Arch Dis Child. 2011;96(3):265-9.

23. Francis $L A$, Birch LL. Maternal weight status modulates the effects of restriction on daughters' eating and weight. Int J Obes. 2005;29(8):942-9.

24. Stifter CA, Anzman-Frasca S, Birch LL, Voegtline K. Parent use of food to soothe infant/toddler distress and child weight status. An exploratory study. Appetite. 2011;57(3):693-9.

25. Grummer-Strawn LM, Scanlon KS, Fein SB. Infant feeding and feeding transitions during the first year of life. Pediatrics. 2008;122(Suppl 2):S36-42.

26. Savage JS, Birch LL, Marini M, Anzman-Frasca S, Paul IM. Effect of the INSIGHT responsive parenting intervention on rapid infant weight gain and overweight status at age 1 year: a randomized clinical trial. JAMA Pediatr. 2016;170(8):742-9.

27. Harris PA, Taylor R, Thielke R, Payne J, Gonzalez N, Conde JG. Research electronic data capture (REDCap)-a metadata-driven methodology and workflow process for providing translational research informatics support. J Biomed Inform. 2009;42(2):377-81.

28. Thompson AL, Mendez MA, Borja JB, Adair LS, Zimmer CR, Bentley ME. Development and validation of the infant feeding style questionnaire. Appetite. 2009;53(2):210-21.

29. Savage JS, Rollins BY, Kugler KC, Birch LL, Marini ME. Development of a theory-based questionnaire to assess structure and control in parent feeding (SCPF). Int J Behav Nutri Phys Act. 2017;14(9).

30. Centers for Disease Control and Prevention. Infant Feeding Practices Study II and its Year Six Follow Up [cited 2015 September 11]. Available from: https://www.cdc.gov/breastfeeding/data/ifps/index.htm.

31. Li R, Fein SB, Grummer-Strawn LM. Association of breastfeeding intensity and bottle-emptying behaviors at early infancy with infants' risk for excess weight at late infancy. Pediatrics. 2008;122(Suppl 2):S77-84.

32. Paul IM, Savage JS, Anzman-Frasca S, Marini ME, Mindell JA, Birch LL. INSIGHT responsive parenting intervention and infant sleep. Pediatrics. 2016; 138(1)

33. Hohman EE, Paul IM, Birch LL, Savage JS. INSIGHT responsive parenting intervention is associated with healthier patterns of dietary exposures in infants. Obesity (Silver Spring). 2017;25(1):185-91.

34. Wright P. Learning experiences in feeding behaviour during infancy. J Psychosom Res. 1988;32(6):613-9.

35. Stifter CA, Moding KJ. Infant temperament and parent use of food to soothe predict change in weight-for-length across infancy: early risk factors for childhood obesity. Int J Obes. 2018;

36. Braden A, Rhee K, Peterson CB, Rydell SA, Zucker N, Boutelle K. Associations between child emotional eating and general parenting style, feeding practices, and parent psychopathology. Appetite. 2014;80:35-40.

37. Rodenburg G, Kremers SP, Oenema A, van de Mheen D. Associations of parental feeding styles with child snacking behaviour and weight in the context of general parenting. Public Health Nutr. 2014;17(5):960-9.

38. Li R, Scanlon KS, May A, Rose C, Birch L. Bottle-feeding practices during early infancy and eating behaviors at 6 years of age. Pediatrics. 2014; 134(Suppl 1):S70-7.

39. Torres SJ, Nowson CA. Relationship between stress, eating behavior, and obesity. Nutrition. 2007;23(11-12):887-94.

40. Braet C, Van Strien T. Assessment of emotional, externally induced and restrained eating behaviour in nine to twelve-year-old obese and nonobese children. Behav Res Ther. 1997;35(9):863-73.

41. Birch LL, Savage JS, Fisher JO. Right sizing prevention. Food portion size effects on children's eating and weight. Appetite. 2015;88:11-6.

42. Galloway AT, Fiorito LM, Francis LA, Birch LL. 'Finish your soup': counterproductive effects of pressuring children to eat on intake and affect. Appetite. 2006;46(3):318-23.

43. Jansen E, Mulkens S, Jansen A. Do not eat the red food!: prohibition of snacks leads to their relatively higher consumption in children. Appetite 2007:49(3):572-7.

44. Blissett J, Haycraft E, Farrow C. Inducing preschool children's emotional eating: relations with parental feeding practices. Am J Clin Nutr. 2010;92(2): 359-65.

45. Liang J, Matheson BE, Rhee KE, Peterson CB, Rydell S, Boutelle KN. Parental control and overconsumption of snack foods in overweight and obese children. Appetite. 2016;100:181-8.

Ready to submit your research? Choose BMC and benefit from:

- fast, convenient online submission

- thorough peer review by experienced researchers in your field

- rapid publication on acceptance

- support for research data, including large and complex data types

- gold Open Access which fosters wider collaboration and increased citations

- maximum visibility for your research: over $100 \mathrm{M}$ website views per year

At BMC, research is always in progress.

Learn more biomedcentral.com/submissions 